\title{
Teaching Methods Exploration in Course of Interchangeability and Measurement Technology
}

\author{
Chang-Rong Qu ${ }^{1}$, Jian-Hong Gong ${ }^{1}$, Xiu-Qi Zhang ${ }^{1}$, Hui-gang Liu ${ }^{2}$ \\ ${ }^{1}$ School of Mechanical, Electrical and Information Engineering, ShanDong University, China \\ ${ }^{2}$ School of Translation Studies, ShanDong University, China \\ quchangrong@163.com, gongjh@sdu.edu.cn, zhangxiuqi2008@163.com, lhuigang@sdu.edu.cn
}

\begin{abstract}
This paper is combined with the 'Interchangeability and Measurement Technology' under course of practice teaching content. It is started with several aspects from how to lead good first class, how to seize the main course, how to adopt modern methods of teaching and to introduces the 'Project' to the actual process. On classroom teaching method for constantly exploration, we eventually designed a methodology that is suitable for mechanical engineering students. Through this method, it can arouse students' enthusiasm on learning this course and let students change their passive learning into active learning. As a result, it can upgrade the purpose of teaching quality.

Index Terms - Teaching methods, Mainline, Modernization Project
\end{abstract}

\section{Introduction}

The Interchangeability and Measurement Technology, belongs to institutions of basic courses of machinery, is a basic subject that closely linked to the machinery industry development. It is also regarded as an important ligament to link design and technology courses. The main task of this course could enable students to obtain the basic theory, basic knowledge and basic skills which are about the aspects of geometric tolerances and measuring technique.

Because this course contains a lot of terminology, standards project and more abstract concepts, symbols, codes, and it involves the knowledge widely, students are lack of professional skills in the production of knowledge and experience. As a result, students generally show no interest in learning this course and the effect of teaching is poor . Therefore, to improve the teaching quality of the course and reform of the teaching method have become a very critical issue. Depend on many years of teaching experience; we concluded the following four aspects for a discussion on the teaching methods.

\section{Discussion on classroom teaching method}

Classroom teaching is the important means of teaching and learning. It is an effective method to guide student to learn and to achieve the purposes of teaching. What we need to be considered and urgent to solve the problem is that how to change the 'Interchangeability and Measurement Technology', which is dishwatery content, into lively and interesting content. So the design of classroom teaching method is very important.

\section{A. Have a good introduction class}

To have a good first lesson we must fully prepare before class. Students should be given a sense of novelty in the new curriculum, so it is important to have a good first introduction lesson. The first we need to talk about of the "Interchangeability and Measurement Technology" is the concept of interchangeability. We can start with something familiar and interesting in our daily life to the students; we can also start with a fragment from the film and television, by using the above ways we can make students understand the implications of interchangeability naturally. We can let students themselves to find out the interchangeable parts through preparing some small parts in class, such as different types of nuts and bolts, let student accept this course and have interest in it emotionally, and then introducing the course in the role of knowledge systems, clearing the learning objectives and requirements for the course. Let students truly understand the importance of learning this course.

\section{B. Grasp the main line}

The content of Interchangeability and Measurement Technology is dispersed and the contents of chapter are disconnected, so it is more difficult to students to learn. If the mainline is caught in the start phase, around the main line to explain the contents of each chapter in a subsequent teaching process, it will be easier for students to understand. First of all, the interchangeability of part is a mainline to impenetrate the course of Interchangeability and Measurement Technology. So how is the qualified part? This is judged by the part's geometry which includes the size, shape, location of the geometric elements of the part, surface roughness, and so on. Only these parameters within the prescribed limits of tolerance, that the parts are qualified. But to ensure the tolerance, we need to use the corresponding measurement technology. We should center on this main line which can let students understand what and why they learn in the teaching process. Second, each chapter has its own main line; we also should start speaking around the main line. For example, when we talking about the chapter of size tolerance and fitting, a machine composed of many parts, components and parts is not isolated. In order to let the machine work properly, the matching of the parts must meet the requirement of job, and it is determined by the size of the parts, so when we talking about the size of the parts, the definition of various sizes were drawn naturally. Only have we known the definition of the 
size, students could be easier to understand the concept of deviation, tolerance, cooperation and cooperate with several types of problems.

\section{Modern means of teaching are adopted}

Traditional teaching methods are mainly composed of blackboard writing, so it is difficult to express some of the concept and content clearly. With the development of computer technology, multimedia teaching mode has become a leading role that is used in today's teaching method. Multimedia can be achieved concept and content, we will be talk about, through animation, sound, images, text and other forms that show in front of the students. It can make abstract visual, reduce the difficulty of teaching, and enhance the teaching of interest and the students' thirst for knowledge.

The section of geometric tolerance is the emphasis and difficulty in the course content. The interpretation of traditional teaching method is mechanical. It is difficult for students to understand and memorize. It can simulate the machining and measuring process by the multimedia teaching such as the perpendicularity tolerance, tolerance range is a distance for and perpendicular to the datum of tolerance values between two parallel planar areas. If only so, it has less effective for students to understand, so we can insert graphics. As shown in figure 1 (a), the mark of 0.05 is the meaning of: surface being measured must be in the distance of $0.05 \mathrm{~mm}$ tolerance zone and perpendicular to the datum axis between two parallel planes. While figure 1 (b) we can draw the curve of the measurement first, then draw two parallel plane, it can deepen the students' impressions by the form of dynamic instead of static display. We also can play the actual processing and measurement video so that the students can have immersive feel.

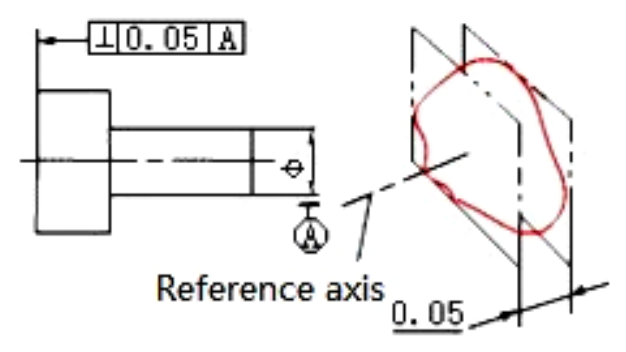

(a)

(b)

Fig1. Perpendicularity tolerance zone

\section{D. 'The project' teaching method}

Students tend to be from books to notes, from concept to concept, from principle to principle in the article -by article, memory and understanding in the learning process, and the result is the wasted effort. Students can accustom a complete way to solve the problem through the 'project 'form of teaching. We choose the "project" mainly is the engineering part drawing and assembly drawing in "interchangeability and measuring technology foundation" of teaching. We should consciously and purposefully select some typical 'project' to introduce the students to close to the reality of 'scene', put forward the corresponding problems and then analyze the "project", teach them to analyze and solve problems or truth, so that students can have a systematic understanding, before the interpretation of the content on each part. For each part to choose the appropriate "project", lets the student access to relevant data, to design the corresponding content, so that we can deepen students' understanding of basic principles and concepts. Students are divided into groups before the end of the course and give them a relatively independent project to handle. Teachers can give requirements and Students themselves responsible for the collection of information, program design, project implementation and final evaluation. Through the progress of the project, students can understand and grasp every aspect of the entire process and the basic requirements. Teacher should be responsible for directing the work in the whole process. It can improve the students to analyze problems and problem-solving skills after introduction of the "project" into the teaching of "interchangeability and Measurement Technology".

\section{Conclusion}

In short, in order to improve the teaching quality of the course "interchangeability and measuring technology", it is necessary not only to enrich and optimization the content of classroom teaching, but also to improve teaching methods. At the same time we must pay attention to combine classroom content and with practice of theory and focus on students' practical skills, analytical problem-solving abilities and innovative design capabilities.

\section{Acknowledgment}

This project was supported by school teaching research fund (No.1050513420006 and No. 1050512420003)

\section{References}

[1] Bo-ping Wang. Interchangeability and Measurement Technology, BeiJing: Machinery Industry Press, Dec 2008.

[2] Long Lu, Shu Zhang. On Teaching Reform and Explore in Course of Interchangeability and Measurement Technology .Science and Technology Information, Third issue of 2010.

[3] Hong-Zhou Zhang .Thinking in Interchangeability and Technical Measurement Teaching. The Science Education Article Collects, Dec. 2008.

[4] Ming-Rong Zhang. Independent institute Interchangeability and Measurement Technology course teaching method design .Science and Technology Information, Sixth issue of 2011.

[5] Chang-Rong Qu. Interchangeability and Measuring Technology Teaching Quality Improvement Methods .Education Teaching Forum, Twelfth issue of 2013. 